\title{
Determination of Air Permeability Property of Air-Laid Nonwoven Fabrics Using Regression Analyses
}

\author{
H.İbrahim ÇELİK \\ Gaziantep University, Faculty of Engineering, Textile Engineering Department, \\ 27310 Şehitkamil/Gaziantep, Turkey
}

\begin{tabular}{l} 
Article Info \\
\hline Article history: \\
Received May $30^{\text {th }}, 2017$ \\
Revised June $15^{\text {th }}, 2017$ \\
Accepted June $17^{\text {th }}, 2017$ \\
\hline
\end{tabular}

\section{Keyword:}

Air-laid nonwoven

Air permeability

Image processing

Porosity

Regression analysis

\begin{abstract}
Air-laid nonwoven fabrics are generally used for hygienic care products such as diaper, adult nappy and sanitary napkins. Air permeability is one of the foremost properties that affect the usage performance of these hygienic care products. In this study, 10 different air-laid nonwoven fabric samples are produced. The porosity ratios of these samples are determined by digital image processing methods. Air permeability of the samples is tested by digital air permeability test device. Then regression analyses were applied to the experimental results using SPSS 21.0 package program. Finally regression equation was obtained for prediction of air permeability by using porosity, thickness and fabric weight.
\end{abstract}

\section{Corresponding Author:}

H.İbrahim ÇELIK

Gaziantep University, Faculty of Engineering,

Textile Engineering Department, 27310

Şehitkamil/ Gaziantep, Turkey.

Email: hcelik@gantep.edu.tr

\section{Introduction}

Nonwoven fabrics are defined as textile products which are produced as textile sheets from staple or filament fibers and entangled by mechanical, chemical, thermal processes. Products from nonwoven fabrics are widely used in application areas such as hygiene, medical, agriculture, civil, home textile, automotive, filtration, ready-made production, food packaging. With wide variety of application areas and production techniques, nonwoven fabric production rate is increased day by day in Turkey, and the production is carried out in Gaziantep, İstanbul and Çorlu, predominantly [1,2].

In the literature there are many studies that show the effects fabric structural parameters; namely pore size, fiber orientation, fiber type, fabric thickness and fabric weight on fabric performance properties such as air permeability, water permeability, absorption capacity, absorption time, breaking strength and tear strength [311]. Aid laid process is a nonwoven web forming process that disperses fibers into a fast moving air stream and condenses them onto a moving screen by means of pressure or vacuum. Air-laid nonwoven fabrics are generally used for hygienic care products such as diaper, adult nappy and sanitary napkins. Air permeability is one of the foremost properties that affect the performance of these hygienic care products. Many researchers investigated the relationship between air permeability and structural features of nonwoven fabrics; namely porosity, fiber diameter, fabric weight, fabric thickness and density [5, 12-18]. Among these structural features, pore size is the determinant parameter for air permeability property. On the other hand, since this type of fabrics have thin structure, determining the pore size properties by using image processing techniques seems possible. In this study, it was intended to use image processing techniques to obtain porosity values of 
the fabric samples and then the regression analysis were used to determine the air permeability properties of fabrics by using porosity, fabric weight and fabric thickness as structural parameters.

\section{Materials and Methods}

\subsection{Material}

In this study, in order to investigate the relationship between the air permeability and porosity properties of nonwoven fabrics, ten air-laid nonwoven fabric samples produced from the same material (40\% viscose, $40 \%$ bicomponent, $20 \%$ polyethylene) with different thicknesses and weights were randomly selected. The physical properties of these samples were given in Table 1. The nonwoven fabric weight and thickness values were measure in accordance with the standards WSP 130.1(05) [19] and WSP120.6(05) [20] respectively.

Table 1. Properties of air-laid nonwoven fabric samples

\begin{tabular}{ccc}
\hline Sample Code & Fabric weight $\left(\mathbf{g} / \mathbf{m}^{\mathbf{2}}\right)$ & Thickness $(\mathbf{m m})$ \\
\hline $\mathbf{N m 1}$ & 53 & 0.57 \\
Nm2 & 53.5 & 0.57 \\
Nm3 & 53.5 & 0.57 \\
Nm4 & 55 & 0.7 \\
Nm5 & 55 & 0.7 \\
Nm6 & 54 & 0.63 \\
Nm7 & 57 & 0.74 \\
Nm8 & 57 & 0.75 \\
Nm9 & 55.5 & 0.67 \\
Nm10 & 55.5 & 0.69 \\
\hline
\end{tabular}

All yarn tests were carried out after conditioning the specimens in a standard atmosphere at $20 \pm 2{ }^{\circ} \mathrm{C}$ temperature and $65 \pm 4 \%$ relative humidity for 24 hours according to the standard of BS EN ISO 139:2005+A1:2011. Tenacity and elongation measurements of yarn samples were achieved with Uster ${ }^{\circledR}$ Tensorapid-4 according to BS EN ISO 2062:2009. Ten tests were performed in each 4 bobbins and reported values represent the average of those test results.

SPSS 22.0 package program at $95 \%$ confidence interval was used for multivariate analysis of variance (MANOVA) in order to determine the significance effect of raw material and blend ratio on yarn tenacity and elongation. Furthermore, Duncan's new multiple range test was provided in order to compare the difference between the means of treatment subgroups of blend ratios in analysis of variance was provided at significance level of 0.05 .

\subsection{Method}

\subsubsection{Porosity measurement}

In order to make regression analysis, the porosity and air permeability of the fabric samples were measured. All the fabric samples were conditioned in standard atmosphere according to TS EN ISO 139 [21] (65 $\pm 4 \%$ relative humidity and $20 \pm 20 \mathrm{C}$ temperature) for $24 \mathrm{~h}$ before the measurements.

Since the nonwoven fabric consists of randomly laid and distributed fibers, space occurs between the fibers. These spaces are called as pores. The porosity of the fabrics can be determined by means of porometer device and image processing application. The porometer device is based on the liquid extrusion through the fabric structure. The image processing method is based on measurement of the light intensity transmitted through the fabric structure. The pixel values of the image frame are assigned according to the light transmission level so that pore regions are seen bright while the regions covered by fibers are seen dark. In this, study the porosity of the fabric samples were determined by using image processing algorithm. The image frames were acquired by using a microscope camera with $60 \mathrm{X}$ magnification. Since the nonwoven fabrics have not got a uniform structure, five image frames were acquired from different place of each sample in order to obtain an average porosity value. So, totally 50 sample image frames were processed. The algorithm given in Figure 1 is applied for all five image frames of each sample. The porosity ratio is determined as average of five measurements of each sample. The image frames get in RGB format were convert to 8 bit gray level images. The image frames were the low pass Gaussian filter. The Gaussian filter makes the image frame smoother and removes certain types of noise [22]. The image frame is convolved with the Gaussian function given Equation (1). 
$h_{g_{\left(n_{1}, n_{2}\right)}}=e^{\frac{-\left(n_{1}^{2}+n_{2}^{2}\right)}{2 \sigma^{2}}}$

where, $\boldsymbol{n}_{1}$ and $\boldsymbol{n}_{2}$ are the locations of the related pixel, $\boldsymbol{\sigma}$ is the variance of neighborhood.

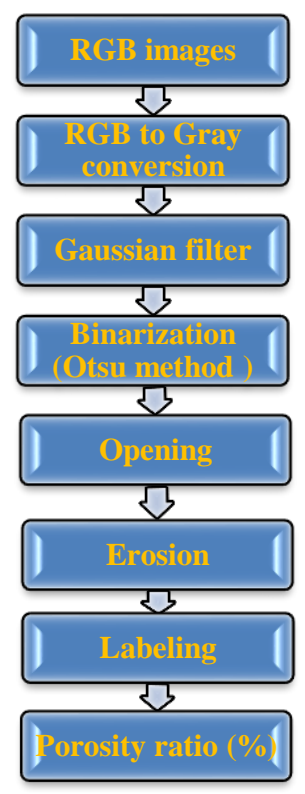

Figure 1. Porosity and pore labeling algorithm

The filtered image is then applied binarization process. Each pixel of the image frame is converted to black or white color according to being below or above threshold level. The threshold level is calculated by using Otsu method [23]. If the pixel value of the image frame is below threshold level, the gray level value of that pixel is allocated as " 0 ". Otherwise, it is set as " $\boldsymbol{I}$ ". The pixel value " $\boldsymbol{l}$ " corresponds to white and " 0 " corresponds to black. In the binary image frame, the white regions indicate the pores and the black regions indicate the fibers. In order to clear the area of pores, morphological operations; opening and erosion are applied in sequence. Opening is a morphological operation of erosion followed by dilation with the same structuring element. The opening operation removes small, isolated objects from the foreground of an image, place them in the background. It smooths the contour of a binary object, breaks the narrow joining regions and eliminates the thin protrusions. In the erosion operation, the center pixel of the structuring element is placed on each foreground pixel value 1 . If any of the neighborhood pixels are background pixels value 0 , then the foreground pixel is switched to background. Finally, the pore areas (white regions) of the binary are labeled. The application of the algorithm on the air-laid fabric sample is given in Figure 2. The porosity ratio of each air-laid fabric sample is calculated as percentage of white pixels to the whole pixels of the binary image.

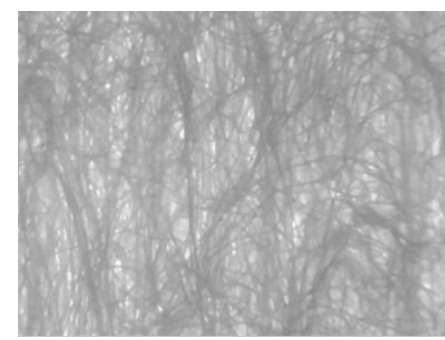

(a) RGB image

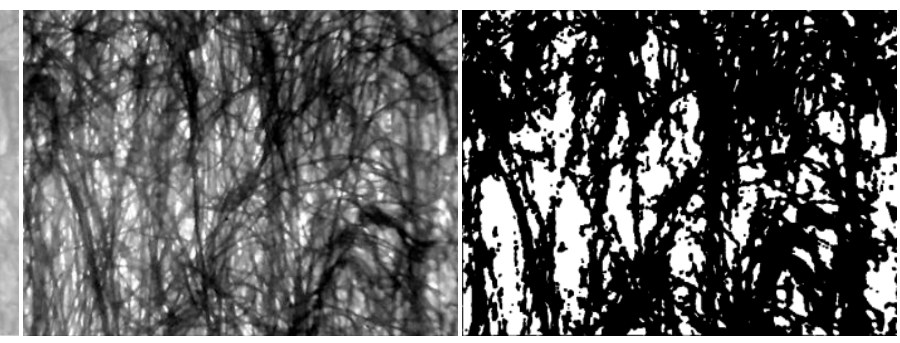

(b) 8 bit Gray level image

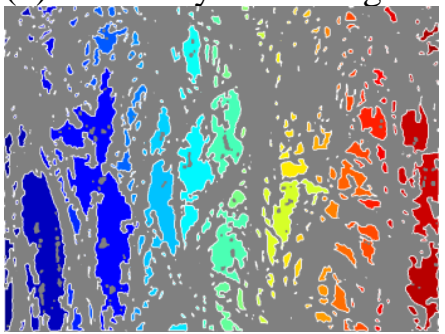

(d) Pore labeled image (c) Binary image 
Figure 2. Algorithm application on sample image

\subsubsection{Porosity measurement}

Air permeability is the velocity of an air flow passing perpendicularly through a test specimen under specified conditions of test area, pressure drop $(\Delta \mathrm{P})$ and time [24]. Air permeability was measured in accordance with the standard WSP 70.1 (05) [24] using digital air permeability test device at $100 \mathrm{~Pa}$ pressure drop and $20 \mathrm{~cm}^{2}$ test area. The measurements were repeated ten times for each fabric sample.

\section{Results and Discussion}

The porosity and air permeability results are given in Table 2 and presented in Figure 3.

Table 2. Air permeability test and porosity measurement results

\begin{tabular}{ccc}
\hline $\begin{array}{c}\text { Sample } \\
\text { Code }\end{array}$ & $\begin{array}{c}\text { Air Permeability } \\
(\mathbf{m m} / \mathbf{s})\end{array}$ & $\begin{array}{c}\text { Porosity } \\
(\%)\end{array}$ \\
\hline $\mathbf{N m 1}$ & 158.6 & 34.50 \\
$\mathbf{N m} 2$ & 163 & 35.63 \\
$\mathbf{N m 3}$ & 150.1 & 35.55 \\
$\mathbf{N m 4}$ & 193.4 & 38.48 \\
$\mathbf{N m 5}$ & 193 & 36.60 \\
$\mathbf{N m 6}$ & 163.1 & 34.72 \\
$\mathbf{N m 7}$ & 183.1 & 38.35 \\
$\mathbf{N m 8}$ & 194.7 & 38.48 \\
$\mathbf{N m 9}$ & 169.5 & 36.71 \\
$\mathbf{N m 1 0}$ & 176.6 & 36.21 \\
\hline
\end{tabular}

As expected from the literature knowledge, there is a direct relation between porosity ratio and air permeability performance of the samples except Nm5. This can be attributed to the fact that the air flow occurs between the pores of the nonwoven fabric structure. As the pores between the fibers constitute the fabric structure increase, more open spaces are provided for air flux. On the other hand, less open spaces between the fibers of the nonwoven fabric lead to higher air drag resistance to air flow. The porosity ratio of the nonwoven fabric depends on many different parameters namely, fiber properties, processing conditions, fabric weight and fiber density. Since whole of the samples consists of the same fiber composition, it can be said that the fabric weight and production process conditions affected the porosity property of the samples.

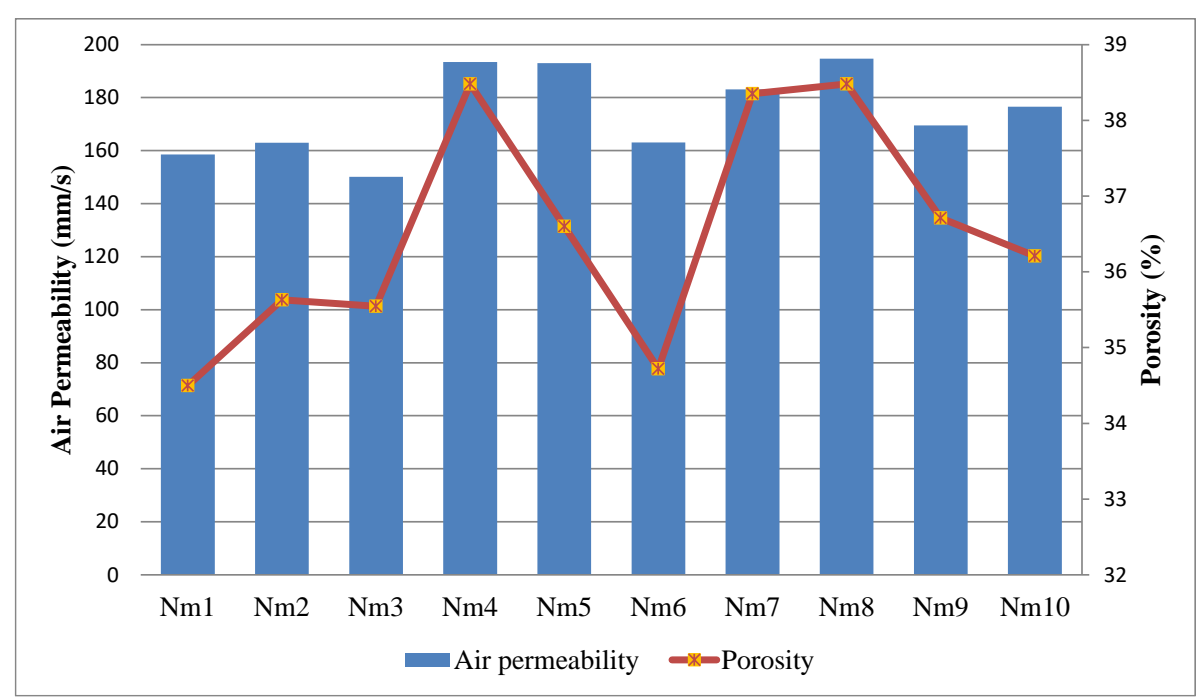

Figure 3. Air permeability and porosity results

On the other hand, fabric thickness also has got effect on the fabric air permeability performance. When the thickness values given in Table 1 are compared with the air permeability results (Figure 4), it can be seen that there is a direct relation with the thickness and air permeability for whole samples. 


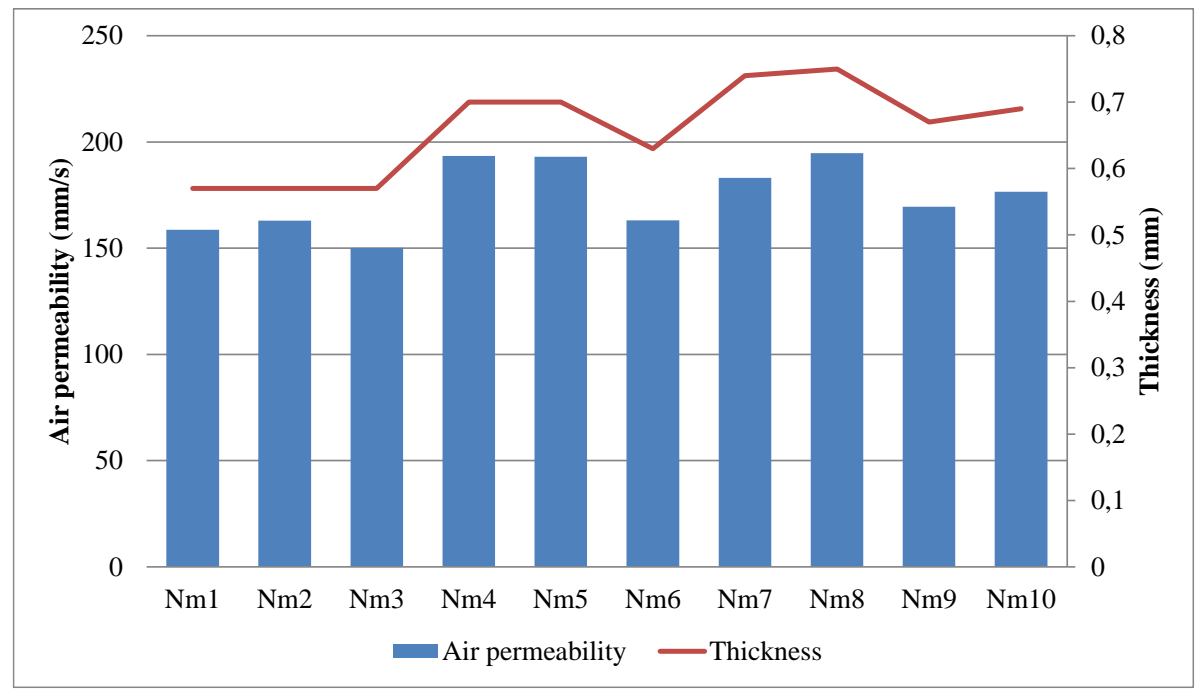

Figure 4. Air permeability results and thickness values

For statistical analyses SPSS 21.0 statistical package program was used. In the first step, correlation analyses were applied to the air permeability, porosity, fabric weight and fabric thickness. The results are given in Table 3. According to correlation analysis, it is seen that there is a strong and positive correlation $(\mathrm{r}=0.825)$ between fabric porosity and air permeability, at $1 \%$ significance level. In the view of thickness effect, it can also be said that there is a strong and positive correlation $(r=0.894)$ between fabric thickness and air permeability, at $1 \%$ significance level. The correlation between the fabric weight and air permeability is determined as $\mathrm{r}=0.752$ at $5 \%$ significance level.

The higher thickness causes a longer path for air passage and so the air flow velocity degreases and vice versa. So, negative correlation between thickness and air permeability is proposed. However, according to the analysis results, strong and positive correlation was obtained. This situation can be attributed to the fact that there is also strong and positive correlation $(r=0.849)$ between fabric thickness and air permeability. As the thickness value increases, the porosity of the samples increases. This situation reveals that porosity increase compensates the diminishing effect of thickness parameter on air permeability. As a result of the correlation results, increased porosity and fabric thickness means high air permeability values for air-laid nonwoven fabric samples.

Table 3. Correlation analysis between air permeability and fabric structural features

\begin{tabular}{|c|c|c|c|c|c|}
\hline & & $\begin{array}{c}\text { Air } \\
\text { permeability }\end{array}$ & Porosity & $\begin{array}{l}\text { Fabric } \\
\text { weight }\end{array}$ & $\begin{array}{c}\text { Fabric } \\
\text { Thickness } \\
\end{array}$ \\
\hline \multirow{2}{*}{$\begin{array}{l}\text { Air } \\
\text { permeability }\end{array}$} & Pearson Correlation & 1 & $0.825^{* *}$ & $0.752^{*}$ & $0.894^{* *}$ \\
\hline & $\begin{array}{l}\text { Sig. (2-tailed) } \\
\mathrm{N}\end{array}$ & 10 & $\begin{array}{c}0.003 \\
10\end{array}$ & $\begin{array}{c}0.012 \\
10\end{array}$ & $\begin{array}{c}0.000 \\
10\end{array}$ \\
\hline \multirow[t]{2}{*}{ Porosity } & Pearson Correlation & $0.825^{* *}$ & 1 & $0.849^{* *}$ & $0.849^{* *}$ \\
\hline & $\begin{array}{l}\text { Sig. (2-tailed) } \\
\mathrm{N} \\
\text { Pearson Correlation }\end{array}$ & $\begin{array}{c}0.003 \\
10 \\
0.752^{*}\end{array}$ & $\begin{array}{c}10 \\
0.849^{* *}\end{array}$ & $\begin{array}{c}0.002 \\
10 \\
1\end{array}$ & $\begin{array}{c}0.002 \\
10 \\
0.947^{* *}\end{array}$ \\
\hline Fabric weight & $\begin{array}{l}\text { Sig. (2-tailed) } \\
\mathrm{N} \\
\text { Pearson Correlation }\end{array}$ & $\begin{array}{c}0.012 \\
10 \\
0.894^{* *}\end{array}$ & $\begin{array}{c}0.002 \\
10 \\
0.849^{* *}\end{array}$ & $\begin{array}{c}10 \\
0.947^{* *}\end{array}$ & $\begin{array}{c}0.000 \\
10 \\
1\end{array}$ \\
\hline $\begin{array}{l}\text { Fabric } \\
\text { Thickness }\end{array}$ & $\begin{array}{l}\text { Sig. (2-tailed) } \\
\mathrm{N}\end{array}$ & $\begin{array}{c}0.000 \\
10\end{array}$ & $\begin{array}{c}0.002 \\
10\end{array}$ & $\begin{array}{c}0.000 \\
10\end{array}$ & 10 \\
\hline
\end{tabular}


Table 4. Multiple linear regression analysis for fabric structural features affecting air permeability

\begin{tabular}{lccccc}
\hline \multicolumn{7}{c}{$\begin{array}{l}\text { Unstandardized } \\
\text { Coefficients }\end{array}$} & $\begin{array}{c}\text { Standardized } \\
\text { Coefficients } \\
\text { Variables }\end{array}$ & $\mathrm{B}$ & Std. & Beta & t & Sig. \\
& & Error & & & \\
(Constant) & 453.144 & 164.962 & & 2.747 & 0.033 \\
Porosity & 4.422 & 2.305 & 0.413 & 1.918 & 0.103 \\
Thickness & 360.830 & 81.133 & 1.569 & 4.447 & 0.004 \\
Fabric weight & -12.348 & 4.013 & -1.084 & -3.077 & 0.022 \\
& a. Dependent Variable: Air permeability & & \\
\hline
\end{tabular}

According to linear regression analysis (Table 4), the regression equation is obtained as below. When three the fabric structure parameters; fabric weight, thickness and porosity are evaluated together in multiple linear regression analysis in terms of effect on the air permeability performance, it can be concluded that the thickness of the air-laid nonwoven fabric has got the most significant effect. The effect of porosity on determining the air permeability performance is less than thickness. The fabric weight has got negative effect on air permeability performance of air-laid nonwoven fabric samples.

$$
\begin{aligned}
& \text { Air permeability }(\mathrm{mm} / \mathrm{s})=453.144+4.422 \text { porosity }(\%)+360.830 \text { thickness }(\mathrm{mm})- \\
& 12.348 \text { fabric mass }\left(\mathrm{g} / \mathrm{m}^{2}\right)
\end{aligned}
$$

\section{Conclusion}

In this study, the relationship between the air-laid nonwoven fabric structural parameters such as; thickness, weight, porosity and air permeability performance were investigated. Totally, ten air-laid fabrics were selected randomly from the products composed of the same fiber types with same blending ratios. The porosity of the fabric samples were determined by using image processing method. For this aim, an algorithm was developed by applying Gaussian low-pass filter and morphological operation.

As a result of regression analysis, it is concluded that there is a strong and positive correlation between fabric structure parameters; thickness and porosity and air permeability performance of air-laid nonwoven fabrics. There is also a strong and positive correlation between fabric thickness and porosity. So, it can be said that the porosity increase compensates the negative effect of the fabric thickness on the air permeability. Since strong and positive correlation between the air permeability and porosity is obtained as expected from the literature knowledge, the developed image processing algorithm can be considered successful on determining porosity measurement.

According to the multiple regression analysis, the most significant effect on air permeability performance is obtained for fabric thickness parameter. The porosity has got less significant effect than thickness parameter. The fabric weight has got a diminishing effect on the air permeability performance in relation to the multiple regression analysis.

\section{Acknowledgements}

Air-laid nonwoven fabric samples used in this study are supplied by Selçuk Group in Gaziantep/Turkey. Author is grateful for firm's cooperation and contribution for this study.

\section{References}

[1]E. Çinçik, 2010, "Experimental and statistical analysis of the properties of polyester/viscose blended nonwovens produced by needle punching method," Çukurova University, PhD Thesis, Engineering Faculty, pp.273, 2010.

[2] W.Albrecht, H. Fuchs, W. Kittelmann, Nonwoven Fabrics. KGaA, Weinheim; Wiley-VCH,Verlag GmbH \& Co, 2003.

[3] A. Rawal, P.V.K Rao, S. Russell, A. Jeganathan, "Effect of fiber orientation on pore size characteristics of nonwoven structures", Journal of Applied Polymer Science,vol.118, pp.2668-2673, 2010. 
[4] M. Dimassi, L. Koehl, X. Zeng, A. Peruwelz, "Pore network modelling using image processing techniques, application to the nonwoven material", International Journal of Clothing Science and Technology, vol.20(3), pp.137-149, 2008.

[5]Ö.B. Berkalp, "Air Permeability \& Porosity in Spun-laced Fabrics", Fibres \& Textiles in Eastern Europ, vol.14(3)-57, pp.81-85, July / September 2006.

[6] M.F. Canbolat, "Structural and mechanical characterization of melt-blown and carded-hydroentangled nonwoven fabrics", Electronic Journal of Textile Technologies, vol.5(2), pp.11-17, 2011.

[7] S. Sayeb, M.B. Hassen, F. Sakli, "Study of some nonwoven parameters influence on the absorption kinetics of liquid", The Open Textile Journal, vol.3, pp.1-5, 2010.

[8] Jr W.R Goynes, K.H. Pusateri, "Determining fiber orientation in nonwovens by digital quantification of microscopic images," in Proc. The National Cotton Council Beltwide Cotton Conference, Jan. 5-9, 2004, San Antonio, TX.p.2784-2795.

[9] A. Rawal, "Structural analysis of pore size distribution of nonwovens", Journal of the Textile Institute, vol.101:4, pp.350-359, 2010.

[10] A. Patanaik, R. Anandjiwala, "Some studies on water permeability of nonwoven fabrics", Textile Research Journal, vol.79(2), pp.147-153, 2009.

[11] J. Payen, P. Vroman, M. Lewandowski, A. Perwuelz, S. Calle'-Chazelet, D. Thomas, "Influence of fiber diameter, fiber combinations and solid volume fraction on air filtration properties in nonwovens", Textile Research Journal, vol. 82(19), pp.1948-1959, 2012.

[12] V. Subramaniam, M. Madhusoothanan, C. R. Debnath, "Air permeability of blended nonwoven fabrics", Textile Research Journal, vol.58(11), pp.677-678, 1988.

[13] R. W. Dent, "The air permeability of nonwoven fabrics", Journal of the Textile Institute, vol.46(6), pp.220-224, 1976.

[14] H. H.Epps, K. K. Leonas, "Pore size and air permeability of four nonwoven fabrics, International Nonwovens Journal, vol.9(2), pp.18-22, 2000.

[15] N. C. Davis, "Factors influencing the air permeability of felt and felt-like structures", Textile Research Journal, vol.28(4), pp.318-324, 1958.

[16] V. K. Kothari, A. Newton, "The air permeability of nonwoven fabrics", Journal of the Textile Institute, vol.65(8), pp.525-531, 1974.

[17] M. S. Atwal, "Factors affecting the resistance of nonwoven needle-punched fabrics", Textile Research Journal, vol.57(10), pp.574-579, 1987.

[18] Y. Yalcin, S. B. Gajanan, "Porosity and barrier properties of polyethylene meltblown nonwovens", The Journal of The Textile Institute, DOI: 10.1080/00405000.2016.1218109, 2016.

[19] WSP 130.1 (05) Standard test method for mass per unit area.

[20] WSP120.6 (05) Standard test method for nonwoven thickness.

[21] TS EN ISO 139 Textiles - Standard atmospheres for conditioning and testing.

[22] 2017, Mathworks website. [Online].

Avaliable: https://www.mathworks.com/help/images/ref/fspecial.html.

[23] R. C. Gonzalez, R. E. Woods, S. L. Eddins, Digital image processing using Matlab" Gatesmark Publishing, LLC, 2009.

[24] WSP 70.1 (05) Standard test method for air permeability of nonwoven materials. 